\title{
The reintroduction of the Andean condor into Colombia, South America: 1989-1991
}

\author{
Alan Lieberman, Jose Vicente Rodriguez, Juan Manuel Paez and \\ Jim Wiley
}

From 1989 to 1991, 22 captive-reared Andean condors Vultur gryphus were released into three protected areas in the Andes of Colombia, South America. The goals of this reintroduction programme were to re-establish populations of these birds in protected habitat where the species had been extirpated, and to train local biologists in the conservation techniques necessary to recover their native condor. All birds were hatched, reared and released according to the protocols established by the US Fish and Wildlife Service and the California Department of Fish and Game for the California condor Gymnogyps californianus. At the time of release, the birds ranged in age from 11 to 26 months. Each bird was fitted with individually numbered wing tags and wing-mounted radio transmitters. Of the 22 released animals, 19 currently survive - a substantial increase to the wild population in Colombia, which had been estimated by Colombian biologists to number only 20 individuals.

\section{Introduction}

The Andean condor Vultur gryphus formerly ranged through the entire length of the Andean chain from western Venezuela to Tierra del Fuego (Murphy, 1936). Today, its range has been considerably reduced (McGahan, 1971). Viable populations survive only in Peru and Argentina. Although it is found from sea level in Peru and to the south, to the north it is generally restricted to isolated mountain peaks (Murphy, 1936; McGahan, 1971, 1972; Calchi and Viloria, 1991).

The Andean condor was formerly widespread in Colombia, but now just a few birds survive in local sites, generally above $3000 \mathrm{~m}$ (Hilty and Brown, 1986). Shooting and habitat destruction were probably responsible for the species's decline (Murphy, 1936; McGahan, 1972). The current population is thought to live mainly in the Santa Marta Mountains (G. Andrade, pers. comm.), but perhaps 2-4 birds still exist in Purace National Park (Paez, 1990a; J. C. Galapsu, pers. comm.), six near Pasto (G. Cantillo, pers. comm.), and an undetermined number in the Nevados de Cocuy (Department of Boyaca, pers. comm.), Huila, and northern Tolima (J. Hernandez, pers. comm.). A flock of 4-5 birds has been recently confirmed on the slopes of Volcan Chiles (Department of Narino, pers. comm.) (J. Wiley, pers. obs., 1990), and even more recently, as many as $12-15$ condors were seen in the same vicinity ( $R$. Arteaga, pers. comm. 1991). In total, current estimates put the Andean condor population in Colombia at about 10 pairs (Paez, 1990a).

Conservationists world-wide have expressed growing concern over the precipitous decline of the Andean condor in Colombia (US Fish and Wildlife Service, 1970). Protection for the species is supported by its listing as an endangered species, both by the US Department of Interior and by Colombia's Instituto Nacional de Desarrollo de los Recursos Naturales Renovables (INDERENA), as well as its listing on Appendix I of the Convention on International Trade in Endangered Species (CITES). In 1988, this concern resulted in a memorandum of understanding between INDERENA and the Zoological Society of San Diego (INDERENA, 1990). INDERENA's Department of Terrestrial Fauna, entrusted 
with the management of Colombia's endangered species, started a conservation effort to re-establish the Andean condor, through the use of captive-produced birds, in areas where it had been extirpated or was nearly extinct, and to train local biologists in conservation techniques that would be required for the long-term management of the species.

\section{Study site}

Three release sites were selected by a group of United States and Colombian biologists familiar with release protocols designed for the California condor Gymnogyps californianus (US Fish and Wildlife Service and California Department of Fish and Game, 1988; Wiley et al., 1991). Sites were selected based on factors including prevailing winds, visibility, location of urban centres, presence of prey species, perching and nesting sites, historical presence of condors, accessibility for biologists and observers, predators, and the presence of conspecific and sympatric avian scavengers. In 1989 Chingaza National Park (CNP), Purace National Park (PNP) and Chiles Indian Reserve (CIR) were considered to be optimum choices for the biological and ecological needs of the birds, as well as having the benefit of governmental control over human activities in the area of release (INDERENA, 1984; Sanchez et al., 1990) (Figure 1). The release sites in all cases were in the Paramo zone $(>3000 \mathrm{~m})$, an alpine vegetation community with frailejon Espeletia spp. and chusque Swallenochloa tessellata, as co-dominants (Cleef, 1981). The climate is typified by heavy fogs, rolling mists, and gusty winds. Annual rainfall is $2000-3000 \mathrm{~mm}$ with an average temperature of $10^{\circ} \mathrm{C}$. During the year spent at the Cerro Leticia (CNP, 3500 $\mathrm{m})$, there were $137 / 365$ days of measurable precipitation (Paez, 1990a). The areas of the national parks are 50,374 ha (CNP), and 83,000 ha (PNP). The Chiles Indian Reserve is estimated to cover about 20,000 ha.

Potential predators in all three areas include spectacled bear Tremarctos ornatus, little spotted cat Felis tigrina and grey fox Urocyon cinereoargenteus (Nowak and Paradiso, 1983)

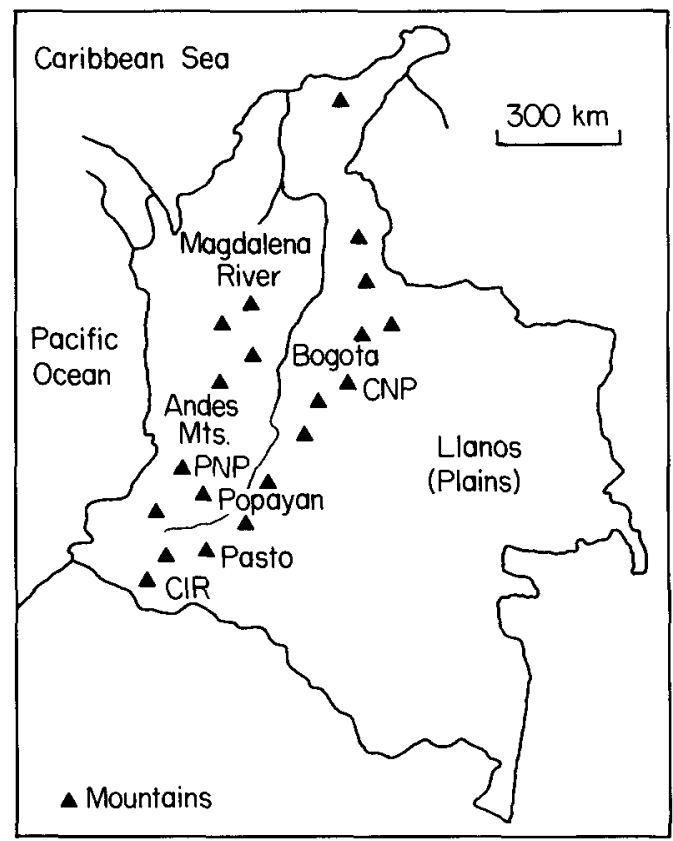

Figure 1. Map showing locations of three sites selected for the release of Andean condors in Colombia, 1989-1991: Chingaza National Park (CNP); Purace National Park (PNP); and the Chiles Indian Reservation (CIR).

The prey species observed in all three release areas include brocket deer Mazama rufina, tapir Tapirus pinchaque, white-tailed deer Odocoileus virginianus goudotti and paca Agouti taczanowski. In addition, limited cattle activity occurs in all three regions, which provides occasional carcasses for the avian scavengers.

Significant interactions occur within and between the carrion-eating species that form the guild of avian scavengers, of which condors are members. (Wallace and Temple, 1978). These relationships are especially important when attempting to predict the normal fledging and weaning patterns of young scavengers. Chingaza NP has two potential avian scavengers, turkey vulture Cathartes aura and black-chested buzzard eagle Geranoaetus melanoleucus, which reach altitudes of more than $3500 \mathrm{~m}$. In Purace NP black vultures Coragyps atratus, turkey vultures, mountain caracara Phalcoboenus carunculatus, and black- 
chested buzzard eagle occur (Barrera, 1990). No confirmed sightings of condors have been documented in Purace since 1986 (Paez, 1990a), but a flock of 5-15 wild condors, all at the level of the release site, $3700 \mathrm{~m}$, survives in the Chiles Indian Reserve.

\section{Condors for reintroduction}

Ten US zoos and governmental organizations produced female Andean condors for use as surrogates in the California condor reintroduction programme (USFWS and CDFG, 1988; Wiley et al., 1991). The concomitant production of surplus males proved to be ideal candidates to initiate a complementary release programme in Colombia.

During the period 1989-1991 three shipments of Andean condors, totalling 22 captivereared birds, were made to three sites in Colombia. The chicks were artificially hatched from eggs contributed by collaborating US institutions and reared in isolation, according to the protocols developed for the California condor, at San Diego Wild Animal Park and Los Angeles Zoo (Toone and Risser, 1987; Kuehler and Witman, 1988) All birds were shipped in Size No. 500 sky kennels by air cargo via Los Angeles and Miami, direct to Bogota or Cali. Birds were transported to their respective release sites by truck and finally by portage to their Paramo release structures. The shipping was uneventful and every effort was made to avoid human contact with the in-transit birds.

\section{Reintroduction facilities and strategies}

The release structure at each site was built of wood and particle board, covered by corrugated metal. In all cases, the structures were built on pylons, and had an outside terraces covered by nylon netting connected to indoor roost boxes. Observation rooms with one-way windows were built adjoining the roosts. The platform at CNP measured $7.4 \times 9.2 \mathrm{~m}$, whereas those at PNP and CIR were $8 \times 7 \mathrm{~m}$. The height of the roost box was $2.5 \mathrm{~m}$ in all cases. The entire platform at all sites was raised to

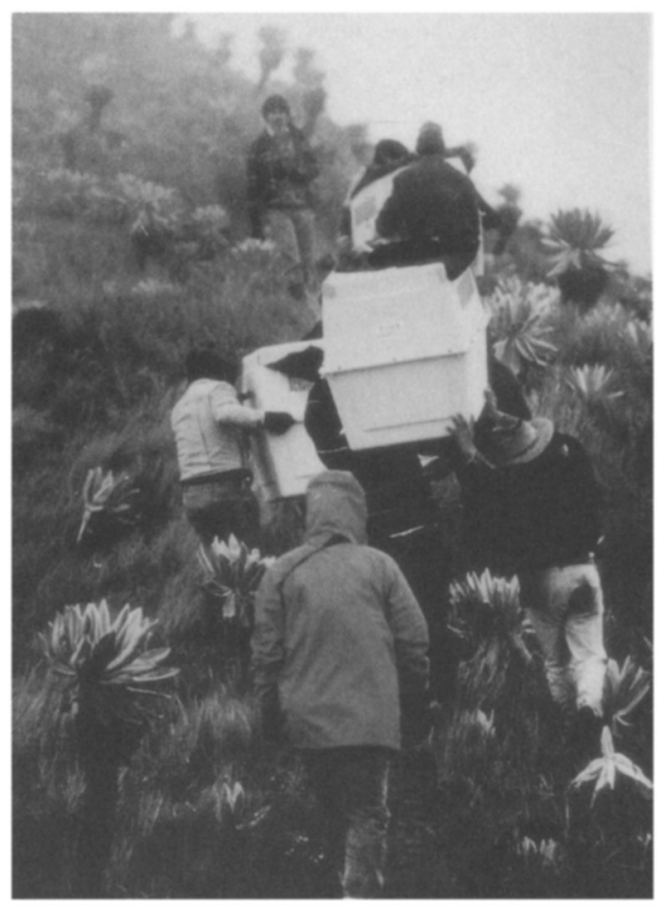

The final steps in transferring the young Andean condors to their release sites requires that each bird be hand-carried over the high-altitude Paramo. The cold, wet conditions can make the final few metres a breath-taking ordeal (Jerry Rife, 1990, Chiles Volcano).

about $2 \mathrm{~m}$ from the substrate. The terrace was approximately one-half the total area of the platform. The release structures were $200 \mathrm{~m}$ (PNP), $1 \mathrm{~km}(\mathrm{CNP})$ and $1.5 \mathrm{~km}$ (CIR) from the closest road. This distance was designed to discourage casual pedestrian traffic, thereby minimizing the exposure of the released animals to human interference. The birds arrived at their respective sites on the following dates: five males on 21 May 1989 (CNP); four males on 3 June 1990 (PNP); five males on 3 June (CIR); four females on 29 June 1991 (CNP); and four females on 1 July 1991 (PNP).

Feeding of the animals during the pre-release period was done on an irregular basis and averaged 2-3 times per week. Food (whole foetal and neonatal calves, chicken parts, and tripe) was always offered through a chute or at night to avoid the association of humans with food.

The release of the birds from their respective roosts took place as early as 17 days 


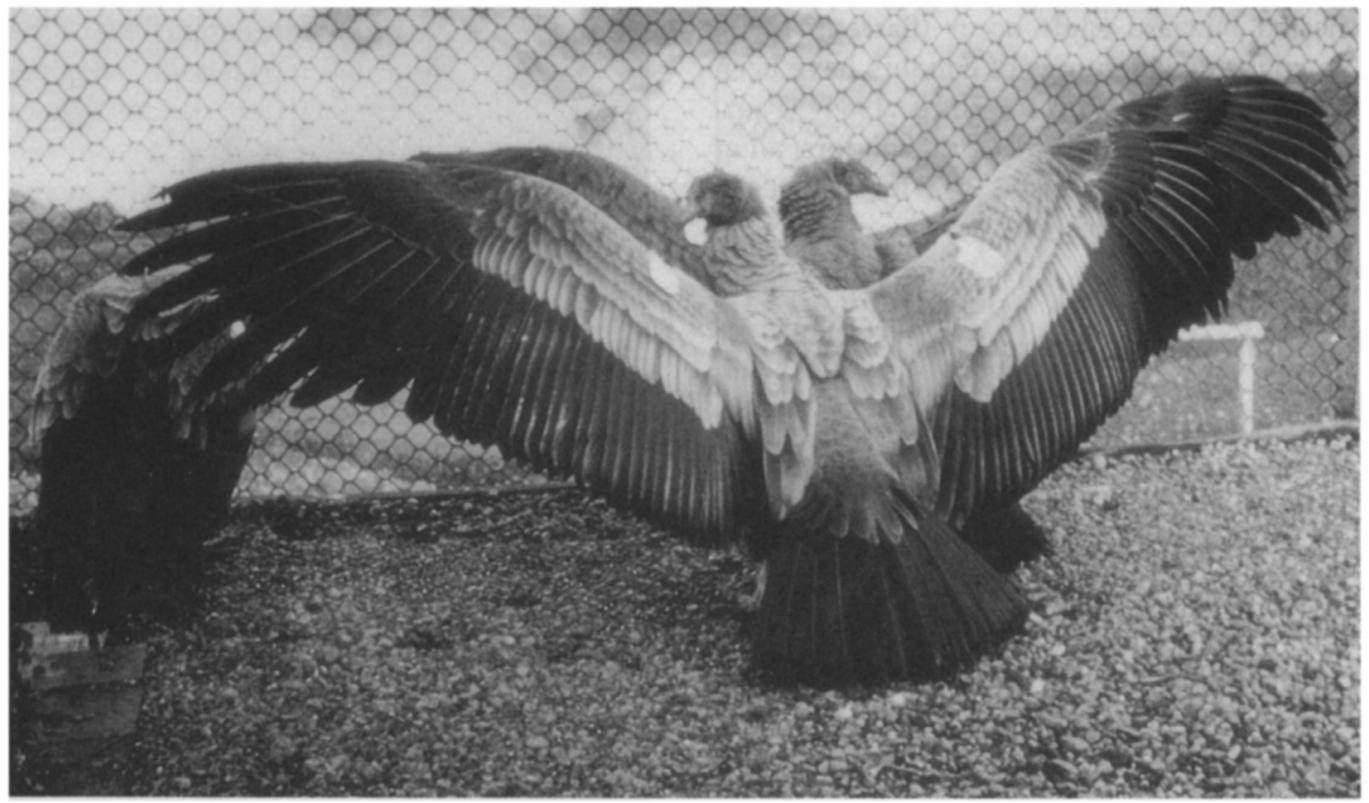

Two young Andean condors stretch their wings, testing the Andean winds in anticipation of their first flight. Note the patagial wing-tags identifying the individual birds. The young birds will spend over 3 months under the netting before being released (Juan Manuel Paez, Paramo Chingaza, 1989).

(CNP, 1989) and as late as 103 days (PNP, CNP, 1991) after the birds arrived. In each release the birds were locked into their roosts in the late afternoon the previous day and the netting was removed from the terrace at night. On the following day, the birds were allowed on to the terrace. Observers were hidden at all times in either the main release structure's observation chamber or in hides built at strategic vantage points in the vicinity. Only in the case of Chingaza (1989) was there a staging of released animals, with three of the birds released before the remaining two. In all other sites the birds were released together.

Once the birds were released, food was offered on an irregular schedule on the release platform and at random sites around the release site itself. Food was rotated among several sites to encourage the birds to search for the offered carrion, rather than expect it in the same sites. Observations were continued after the birds were set free and when visual contact was not possible, radio checks were made and logged on topographic maps.

Radio transmitters and coloured plastic tags were attached to one or both wings of the bird from 4 to 14 days after the irstallation of the birds at their respective sites (Wallace, Parker and Temple, 1980; Paez, 1990c). Radio transmitter and tag attachment followed the protocols described for use with the California condor (USFWS and CDFG, 1988; Wiley et al., 1991). The telemetry equipment was a handheld dual yagi antenna, with signals produced by a combination of solar- and battery-powered single-stage transmitters. The birds were monitored from readings taken of their daily movements from mobile positions at vantage points throughout the study area, taking care to conceal the field workers from view of the birds.

\section{Reintroduction of condors}

From 1989 to 199122 Andean condors were reintroduced into Colombia. Of these, 19 survive: three males in CIR; three males and four females in PNP; and five males and females in CNP. This makes a significant contribution to Colombia's pre-release estimate of 10 pairs of wild condors. Two of the released animals 


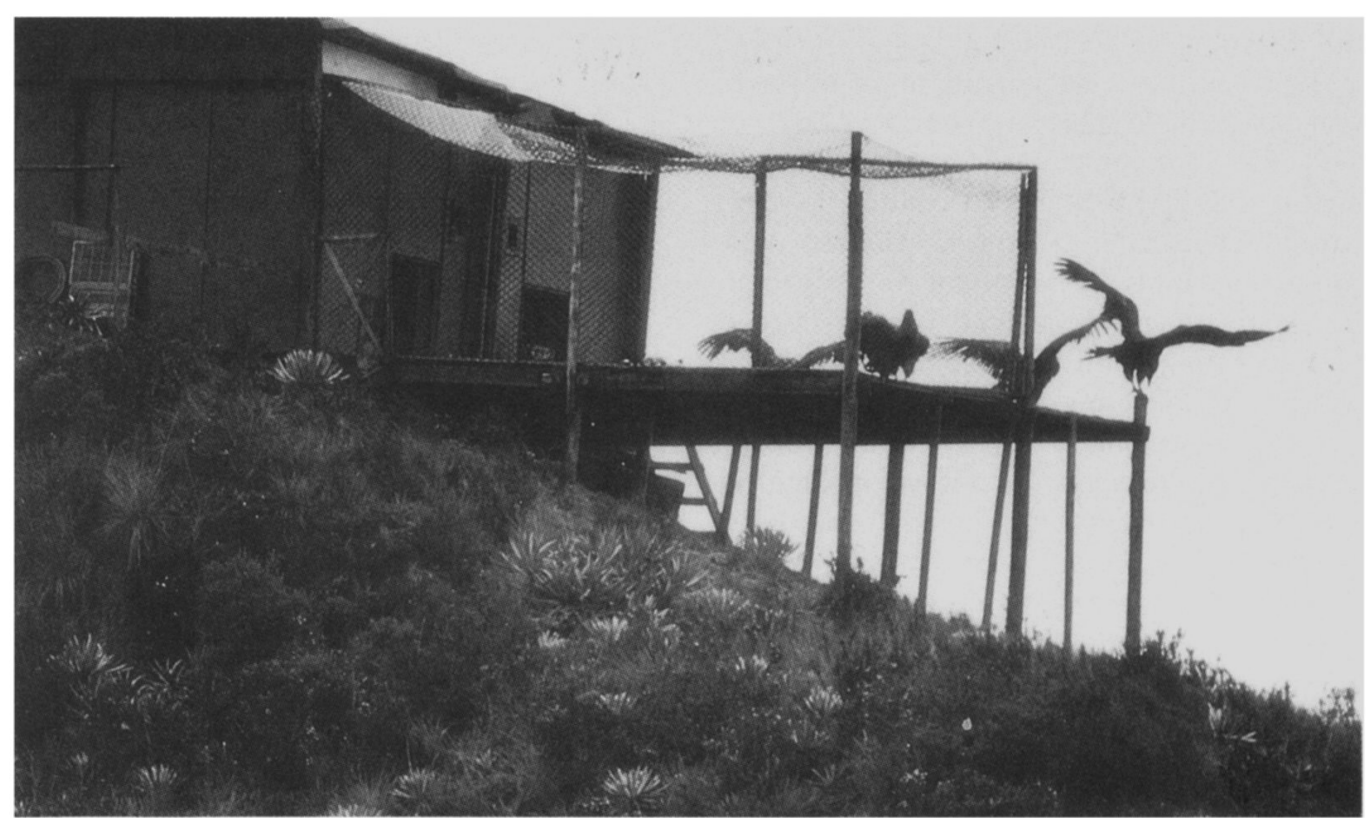

The first release of young Andean condors over the Paramo Chingaza in 1989. The first flights were short and unsteady, soon becoming strong and confident (David Clendenen, US Fish and Wildlife Service).

died in May, 1991 at the CIR site, about 300 days after release, and a third died in July 1991 in Purace, about 360 days after release. Post-mortem examinations were performed on all three animals. The only indication of a possible cause of death was a gastro-intestinal infection in the Purace bird. Perhaps of greater significance was the absence of trauma, or of any indication of human impact, i.e. lead shot either in the muscles or in the digestive tracts.

In four of the five releases, the young condors demonstrated little difficulty in taking their first flights. In the first group of three birds released after only 17 days under the netting (CNP, 1989), there was a need to recapture the birds (a cycle repeated three times). These three animals showed a reluctance to fly, and were felt to be incapable of returning to the release site for food. Only after an additional 30 days enclosed in the roost were the birds re-released, followed by the hoped-for return of the birds to the feeding terrace within 2-3 days (Paez, 1989).

Among the five condors released in CNP (1989), flight distances increased from $<1 \mathrm{~km}$ to about $10 \mathrm{~km}$ after the first 6 months. After 6 months the four birds in PNP (1990) were flying distances of $1.5-16 \mathrm{~km}$ in sustained flights. After 1 year, birds at both CNP and PNP were consistently maintaining flights of $16 \mathrm{~km}$. It has been calculated that the five birds in CNP had established a flight area of about $130 \mathrm{sq}$ $\mathrm{km}$ after 1 year, and close to $200 \mathrm{sq} \mathrm{km}$ after 2 years (Paez, 1990b). This area is less than that seen in young condors released in Peru (Wallace and Temple, 1987). In both CNP and PNP, the progressively longer flights were made without the benefit of guide birds, i.e. other condors.

One of the goals of this programme was to re-establish condors in their historical range. A measure of success is the speed with which the reintroduced animals are integrated into the native ecosystem. Part of this integration involves the interaction between the released condors and other avian scavengers in the area. Such interactions were recorded. In PNP, the young condors flew and ate with mountain caracara and black vultures. The black vultures ate the human-offered carrion only if the condors were not in the area or if the condors had already eaten and their crops were 
full (Barrera, 1990). This inter-specific hierarchy is also consistent with those observations made by Wallace and Temple (1987). In CIR, the captive-reared condors were observed eating with the wild condor flock on naturally occurring carrion (G. Gomez, pers. comm.). Another observation was made in which a young female wild condor begged from a young captive-reared animal, which obliged by vomiting for the wild bird ( $R$. Arteaga, pers. comm.).

Within the first year of release, feeding on natural carrion has been noted in all three sites. In Purace, 5 months after release, one individual was not seen at the various feeding sites for 32 days. When finally recaptured upon its return, the bird was found to be in good condition, without any loss of weight. In $\mathrm{CNP}$, there have been periods of up to 20 days in which no birds returned to eat the offered carrion (Paez, 1990a). The first visual verification of a natural feeding in CNP was of a condor eating a mountain paca in March 1990, 8 months after release in July 1989.

\section{Discussion}

It is interesting to note the difference in the development of the foraging patterns demonstrated by the young condors in Chingaza and Purace, compared with condors of a similar age released into the arid mountains of western Peru (Wallace and Temple, 1987). After more than a year of freedom, the Colombian animals had a foraging flight distance of 20 $\mathrm{km}$ from their release point. The birds in western Peru were flying over $100 \mathrm{~km}$ at this stage in their development. It may be that the daily fog and rain in the Colombian Paramo discourage long, sustained flights. Also, in both Purace and Chingaza, the only two sites for which flight distance data are available, the released animals did not have the benefit of being exposed to a wild flock of foraging condors. The released condors in Peru quickly associated with a wild flock of condors and adopted the native feeding patterns (Wallace and Temple, 1987). It is felt that the young birds require 1 month or more under netting at the release structure before being released. This period of time is important for physiological acclimatization, familiarization with visual landmarks, neophyte bird's observations of conspecific and sympatric avian scavengers, and to become familiar with prevailing wind patterns.

The general success of the first five groups of captive-reared Andean condors released in Colombia has encouraged INDERENA to proceed with the release programme, expanding both the numbers of animals and release sites. The programme will include a fourth release site in late 1992 or 1993 in the Department of Quindio in Los Nevados National Park. The contributing members of the US zoo community will continue to provide surplus eggs and chicks from the captive Andean condor population to further Colombia's reintroduction programme. In order for this programme to succeed, it will be crucial that the released animals remain under the surveillance and protection of the managed area system of INDERENA. It is also critical that the local people be educated and informed as to the importance of this programme for the future survival of their national bird. To date, there has been no human harassment of the released animals. This is in part due to the education programme that is taking place in the surrounding communities, sponsored by INDERENA and Fundacion par la Educacion Superior (FES).

Encouraged by the success of the Colombian reintroduction programme, INPARQUES, the Venezuelan equivalent of INDERENA, will be initiating a similar programme in 1992 with funding by the Banco Andino of Venezuela. A team of Venezuelan field biologists will train with the Colombians in Chingaza National Park to gain experience needed to perform the same tasks in the Paramo de Piedras Blancas in the Sierra de la Culata, Venezuela. Combining resources, experience and young condors hatched and reared in North American zoos, the Andean condor will be reintroduced into Venezuela by the end of 1992.

Especially encouraging is the positive response from the general Colombian public 


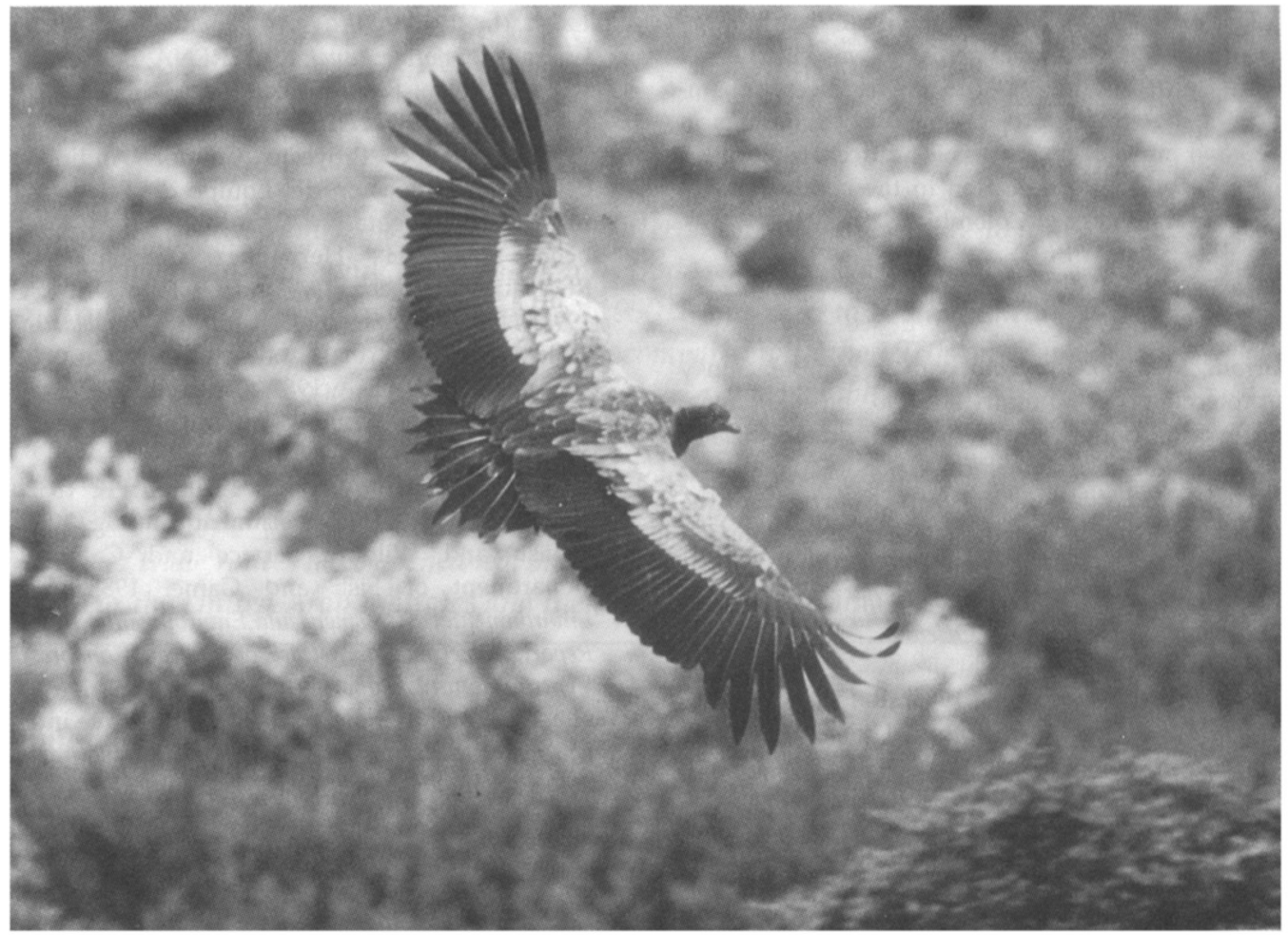

A young male Andean condor soars over the Paramo Chingaza for the first time in over 70 years. Current estimates of the wild condor population in Colombia is fewer than 30 birds. The 19 captive-reared condors make a substantial increase to the population (Juan Manuel Renjifo, Paramo Chingaza, 1989).

over the entire condor release programme. INDERENA has taken on a new and exciting role as a proactive conservationist institution. This programme has brought the purpose and role of INDERENA to the attention of a country troubled by civil war and drugs. In addition, the pride and confidence generated by each successive release of condors has brought the morale and self-esteem of INDERENA to a new high. Media coverage in the press, and on radio and television has been timely and dramatic. It is hoped that the public concern over the plight of just one of Colombia's native endangered species will invoke similar interest for other threatened species. Tropical conservation of species and habitat diversity will depend on such a public response. The condor release programme represents much more than the short-term salvation of one species. It has served as a focus for the entire spectrum of dwindling natural diversity in Colombia.

\section{Acknowledgments}

The authors would like to acknowledge the substantial efforts made on behalf of the condor reintroduction programme by the resources and personnel of FES, especially Jorge Orejuela, Guillermo Cantillo, and the GARUN group, especially Jose Orlando Feliciano, and the entire Chiles Indian community led by Chief Reinaldo Arteaga and his family. In Chingaza, the Aquaduct Company of Bogota, and especially Nestor Fonseca, provided support and encouragement for the release programme. Key personnel in the field were Miguel Barrera and German Gomez in Purace and Chiles, respectively. Equally instrumental in ensuring the success of this programme were contributions in resources, eggs and personnel from Buffalo Zoo, Dallas Zoo, Los Angeles Zoo, Metro Miami Zoo, Oklahoma City Zoo, Patuxent Wildlife Research Center, Potawatomi Zoo, San Antonio Zoo, San Diego Zoo, and the San Diego Wild Animal Park. Additional financial contributions were made by the ICBP-Pan American Section and the US Fish and Wildlife Condor Recovery Program and Office of International Affairs. 
This article is dedicated to the memory of one of its authors, Juan Manuel Paez, who was killed on 24 February 1992 at the age of 26 . He had been a champion of the condor project since its beginnings in 1989 and much of its success is a direct result of his tireless work and dedication to the condor and to the natural heritage of Colombia.

\section{References}

Barrera, M. 1990. Proyecto para la recuperacion y proteccion del condor Andino en Colombia. Proyecto Condor Andino-Purace. Informe Anual de Actividades-1990. INDERENA, Bogota.

Calchi, R. and Viloria, A.L. 1991. Occurrence of the Andean condor in the Perija Mountains of Venezuela. Wilson Bull. 103 (4), 720-722.

Cleef, A.M. 1981. The Vegetation of the Paramos of the Colombian Cordillera Oriental. PhD thesis. Tijksuniversiteit te Utrecht.

Hilty, S.L. and Brown, W.L. 1986. A Field Guide to the Birds of Colombia. Princeton University Press, Princeton, New Jersey.

INDERENA. 1984. Colombia - Parques Nacionales. Bogota.

INDERENA. 1990. Convenio celebrado entre el INDERENA y el Zoologico de San Diego. Documento Numero 49/90, Bogota.

Kaseilke, S. and Wallace, M. 1990. Andean Condor Studbook. Los Angeles Zoo, Los Angeles, California.

Kuehler, C. and Whitman, P. 1988. Artificial incubation of California condor, Gymnogyps californianus, eggs removed from the wild. Zoo Biology, 7, 123-132.

McGahan, J. 1971. The condor, soaring spirit of the Andes. National Geographic, 139 (5), 684-709.

McGahan, J. 1972. The Behavior and Ecology of the Andean Condor. PhD thesis, University of Wisconsin, Madison.

Murphy, R.C. 1936. Oceanic Birds of South America. American Museum of Natural History, New York.

Nowak, R.M. and Paradiso, J.L. 1983. Walker's Mammals of the World. 4th Edition. John Hopkins University Press, Baltimore, Maryland.

Paez, J.M. 1989. Proyecto condor Andino - Zona 1. Parque Nacional Natural Chingaza. Informe Anual. INDERENA, Bogota.
Paez, J.M. 1990a. Proyecto condor Andino Chingaza. Informe Anual. INDERENA, Bogota.

Paez, J.M. 1990b. Proyecto condor Andino. Informe Nacional. INDERENA, Bogota.

Paez, J.M. 1990c. Proyecto Condor Andino Chingaza. Evaluacion del Equipo de Telemetria. INDERENA, Bogota.

Sanchez Paez, H., Hernandez Camacho, J.I., Rodriquez Mahecha, J.V. and Castano Uribe, C. 1990. Nuevos Parques Nacionales de Colombia. INDERENA, Bogota.

Toone, W. and Risser, A. 1987. Captive management of the California condor. Int. Zoo Yearbook, 27, 50-58.

US Fish and Wildlife Service. 1970. 35 FR: 18320. December 2 1970. US Government Printing Office.

US Fish and Wildlife Service and California Department of Fish and Game. 1988. Joint Environmental Assessment and Environmental Impact Report. Experimental Release of Andean Condors in Ventura County, California.

Wallace, M. and Temple, S. 1978. Competitive interactions within and between species in a guild of avian scavengers. Auk, 104, 290-295.

Wallace M., Parker, P. and Temple, S. 1980. An evaluation of patagial markers for Cathartid vultures. J. Field Orn. 51, 309-314.

Wallace, M. and Temple, S. 1987. Releasing captivereared Andean condors to the wild. J. Wildl. Manage. 51, 541-550.

Wiley, J.W., Austen, G., Clendenen, D., Giese, A., Ledig, D., Leete, A., Lindsey, G., Mesta, R., Pedersen, H., Wallace, M., Kasielke, S., Conzales, B., Toone, W., Shima, A. and Lieberman, A. 1991. Protocols for Releases of California Condors. US Fish and Wildlife Service, Ventura, California.

Alan Lieberman, Curator/Herpetology, San Diego Zoo, PO Box 551 San Diego, California 92112, USA.

Jose Vicente Rodriguez, Conservation International, AA 85530, Santafe de Bogota, Colombia.

Juan Manuel Paez, Coordinador General Programa Condor Andino, AA 85530, Santafe de Bogota, Colombia

Jim Wiley, Grambling Cooperative Wildlife Program, Grambling State University, PO Box 4290, Grambling, Louisiana 71245, USA. 